\title{
Un "ethos" para el gobierno y la administración: un debate entre el liberalismo y el jesuitismo políticos*
}

\author{
JULIÁN SAUQUILLO \\ Universidad Autónoma de Madrid
}

\begin{abstract}
RESUMEN. Este estudio rebate las tesis de Carl Schmitt que conciben al catolicismo, y al jesuitismo en particular, como una gran complexio oppositorum que reúne tanto al conservadurismo como al izquierdismo bajo una misma unidad absoluta representada por las formas del Papa. El "ethos" de obediencia postulado por la Compañía de Jesús contribuyó decisivamente a la formación de una Administración que rebasa el marco de la burocracia eclesiástica. Sustituyó la educación renacentista por una educación de cuño tomista, decisiva en la formación del "ethos" disciplinado del funcionario que actúa sine ira et studio. Pero fracasó en la pretensión de remplazar la vitalidad, el naturalismo y la confrontación de opiniones del liberalismo bajo la mencionada complexio oppositorum.
\end{abstract}

Palabras clave: Jesuitismo, "ethos" de obediencia, burocracia eclesiástica, Ribadeneira, Maquiavelo, Schmitt.
ABSTRACT. This survey refutes Carl Schmitt's thesis that hold catholicism, and jesuitism in particular, as a great complexio oppositorum which joins both conservatism and leftism under a same absolute unity represented by the papal forms. The "ethos" of obedience postulated by the Society of Jesus decisively contributed to the formation of an Administration that surpasses the ecclesiastic burocracy's framework. It replaced the Renaissance education for an education with a Thomist stamp, decisive in the fashioning of the disciplined "ethos" of the official who acts sine ira et studio. But it failed for its attempt to replace the vitality, the naturalism and the confrontation of opinions of Liberalism under the aforementioned complexio oppositorum.

Key words: Jesuitism, "ethos" of obedience, ecclesiastic burocracy's, Ribadeneira, Machiavelli, Schmitt.

“(...) ¿Qué quiere decir esto? ¿Qué camino es este por donde entramos? ¿Qué nueva empresa es esta que acometemos? ¿Qué manera de guerra es esta en que andamos? (...)” Pedro Ribadeneira, La vida de San Ignacio de Loyola (1587)

"Considerando en el Señor nuestro, nos ha parecido en la su divina Magestad, que mucho y en gran manera importa que los Superiores tengan entera inteligencia de los inferiores, para que con ella los puedan mejor regir y gobernar, y mirando por ellos enderezarlos mejor in viam Domini." Ignacio de Loyola, Fórmula del Instituto (1540).

* Este trabajo fue redactado inicialmente con ocasión de un encuentro titulado "Ignacio de Loyola y Baltasar Gracián”, organizado por la Duke University y la Universidad de Murcia en Úbeda, los días 13 y 14 de marzo de 2005, y dirigido por los profesores Alberto Moreiras y José Luis Villacañas. 


\section{Una “askesis" liberadora, otra para el disciplinamiento}

El "ethos" del jesuitismo tiene su base en la filosofía antigua y, fundamentalmente, en el estocismo. La expresión exercitium spirituale de Ignacio de Loyola tiene precedentes en el antiguo cristianismo. Se corresponde con la askesis o melete del cristianismo griego. Frente al sufrimiento producido por las pasiones, la ascesis procura una terapia filosófica ${ }^{1}$. La vigilancia y la tensión constantes de los griegos centraban la atención en el momento presente y querían acabar con las pasiones suscitadas por objetos cuyo dominio no depende de nosotros. Los antiguos tenían muy clara la distinción fundamental entre la libertad -lo que depende de nosotros- y la naturaleza -lo que no depende de nosotros ${ }^{2}$. Muchos de los deseos suscitados por los objetos externos eran innecesarios. De ahí que la askesis consistiera en desprender de nuestro pensamiento todas las imágenes que nos causan dolor, para lograr alivio y serenidad. Los ejercicios espirituales antiguos eran una técnica de autoconocimiento mediante el autoanálisis y el diálogo. Trataban de liberar al pensamiento de todo lo carnal y volver hacia la actividad del intelecto. La conversión consistía en un desgarramiento del ascético respecto de la vida cotidiana. La introspección, la escritura, el examen de conciencia son técnicas para lograr la autonomía del asceta. Con esta autoexigencia ascética se trataba de vigorizar al sujeto a través del encarnamiento del "pneuma", una energía cósmica e inmanente al mundo cotidiano. Aquel que vivía en este estado de tensión moral encontraba la finalidad de la vida. En el primer estoicismo no existían "preferibles" sino un formalismo axiológico. Incluso en Marco Aurelio -aunque ya en el último estoicismo sus rasgos más antiguos se hayan modificado- se encuentran alusiones a cómo si el arquero está en tensión, no importa donde esté la diana, la flecha encontrará su centro, el objetivo, de forma perfecta (Meditaciones, Libro VIII, $\left.\mathrm{n}^{\mathrm{o}} \mathrm{LX}\right)^{3}$. Se trataba de una filosofía centrada en la autonomía del sujeto y no en la jerarquización de unos sobre otros ${ }^{4}$. En cambio, con el cristianismo, la obediencia al director espiritual supuso un acatamiento absoluto del superior. Las dimensiones trascendentes del amor a Dios y a Cristo transfiguraron todas las virtudes antiguas. La renuncia a la voluntad es consiguiente al amor divino. El director espiritual cristiano decide absolutamente la alimentación, la manera de vestir, los oficios o los afectos del monje monástico5.

1 André-Jean Voelke, La philosophie comme thérapie de l'âme. Etudes de philosophie hellénistique (prefacio de Pierre Hadot), París, Editions Universitaires de Fribourg, 1993.

2 Epicteto, Pláticas por Arriano, I-IV (traducción de Pablo Jordán de Urríes y Azara), Barcelona, Ediciones Alma Mater, 1958.

${ }^{3}$ Marco Aurelio, Ta eis heautón (traducción, prólogo y notas de Bartolomé Segura Ramos Meditaciones, Madrid, Alianza Editorial, 1985, p. 111).

${ }^{4}$ Pierre Hadot, La citadelle intérieure. Introduction aux Pensées de Marc Aurèle, París, Fayard, 1992, 386 pp.

5 Pierre Hadot, "Exercices spirituels", "Exercices spirituels antiques et "philosophie chrétienne", Exercices spirituels et philosophie antique, París, Études augustiniennes, (2 a ed. revisada y aumentada 1987), pp. 11-74. 
La tradición agustina hizo acopio de los ejercicios espirituales del último estoicismo -Séneca, Marco Aurelio y Epicteto- para darlos un sentido nuevo. Ambas tradiciones, antigua y medieval, adoptan unos "ejercicios espirituales" que pretenden el "análisis de uno mismo" constante. Pero la gran diferencia entre uno y otro es que el análisis de los estoicos es privado, mientras que el de los cristianos es público y comprende una ritualización y una representación de la confesión, el pecado y la penitencia. Mientras las Pláticas de Epicteto inciden en una asunción de reglas lograda mediante la lectura y la memorización individual o con un maestro, los ejercicios espirituales católicos se organizan dentro de un proceso de selección de quienes van a someterse a las reglas del monasterio o de la Compañía. El ejercicio mnemotécnico estoico es verbal, mientras la penitencia cristiana produce una disociación disciplinaria sobre el creyente. Además, mientras la relación del discípulo con el maestro antiguo era instrumental y temporal hasta que el joven alcanzara la vida feliz y autónoma, la vida monacal se elige de por vida -los Ejercicios Espirituales y las Constituciones de Ignacio de Loyola la conciben como una "decisión inmutable"6_. La obediencia cristiana supone un control absoluto del inferior por el superior que no conduce a su autonomía sino a su sacrificio y mortificación. En última instancia, el fin del cristianismo es la salvación del alma, conducirla del tiempo real y la vida a la muerte y la eternidad. Por ello, el creyente debe acepta una serie de obligaciones monásticas, asume ciertos libros como dogmas, se confiesa a sus superiores... ${ }^{7}$ Todo este labrado de la personalidad del cristiano se alejó de la vieja máxima: que cada cuerpo sea "causa sui" o, dicho spinozistamente, que "cada cuerpo sea causa de si y ningún cuerpo sea causa de los otros".

Los Ejercicios Espirituales y las Constituciones de Ignacio Loyola son una muestra ejemplar del procedimiento de los ejercicios espirituales en los monasterios bajo una organización comunitaria jerárquica. El fin en este espacio vigilado -sometido constantemente a la disciplina de los trabajos despersonalizadores y a la confesión ${ }^{8}$ a los superiores- no es la autonomía sino la obediencia eterna ${ }^{9}$. Entre los ejercicios espirituales cristianos solitarios de la Vida de Antonio (357) de Atanasio y las reglas monásticas de obediencia, funcionalidad jerárquica, entrega absoluta, desprendimiento de todo el mundo exterior, acatamiento ciego de la autoridad y vivencia autosugestiva de los pasajes aconsejados de la Biblia sólo

${ }^{6}$ Ignacio de Loyola, Ejercicios espirituales, Obras de San Ignacio de Loyola, Madrid, Biblioteca de Autores Cristianos, 1997, pp. 221-306; Ignacio de Loyola, Constituciones, op. cit., pp. 464-646, p. 492.

7 Michel Foucault, "Tecnologías del yo" (traducción de Allendesalazar, introducción Miguel Morey), Tecnologías del yo y otros textos afines, Barcelona, Paidos / I.C.E.-U.A.B., pp. 80-86.

${ }^{8}$ Michel Foucault, Histoire de la sexualité. I. La volonté de savoir, París, Gallimard, 1976, pp. 76-84 (traducción de Ulises Guiñazu Historia de la sexualidad. I. La voluntad de saber, Madrid, Siglo XXI, 1977 (4 $4^{\mathrm{a}}$ ed. 1978), pp. 73-80)

9 Vid. Ludwig Marcuse, Ignatius Loyola, Zurich, Diogenes Verlag AG., 1997, (traducción de Mercedes Figueras, Ignacio de Loyola. Un soldado de la Iglesia, Barcelona, Edhasa, 1997). 
existe un parecido difuso. La escritura de nuestros actos y nuestros pensamientos para que cobren permanencia y se revelen a los otros, como técnica espiritual recogida por Atanasio, se asemeja a los ejercicios espirituales estoicos ${ }^{10}$. A su vez, la Vida de Antonio se quiere ejemplo vivo para cristianos y paganos, supone una dura ascesis que suscitó amplio número de seguidores, pero que nunca renunció a la vida en las montañas. Antonio postula la furia de la Iglesia ante la corrupción, la bondad trasformadora de la fe en vez del "arte de las palabras" o de los silogismos filosóficos, el anatema de los herejes, hace milagros, aconseja a los monjes, lucha con el demonio, defiende el martirio interior tanto más duro ${ }^{11}$, pero sus reglas no aspiran a la creación de una organización constitucional de la religión interior como pública. En el reforzamiento e institucionalización de los ejercicios espirituales monásticos, la Compañía de Jesús va a tener un protagonismo fundamental ${ }^{12}$.

\section{La organización burocrática de un ejército de tropas ligeras}

Si partimos de una escisión meridiana entre los cometidos mundanos del catolicismo y del protestantismo, la Compañía de Jesús ha tenido un papel decisivo en la delimitación de esta separación de religiones desde el Concilio de Trento (1545-1563). Su mayor afán fue contrarrestar la fuerza diabólica del protestantismo. A tal efecto, dispuso de una política versátil. Al catolicismo, y al jesuitismo en particular, se le atribuyó una complexio oppositorum capaz de integrar todas las formas de gobierno clásicas. El catolicismo quiso, verdaderamente, realizar su vocación universal como un imperio inédito - ni el romano, ni el inglés- que se adaptara a las más diversas circunstancias. Así las Constituciones persiguen la "uniformidad" y "universalidad" de todos sus centros, pero Ignacio de Loyola considera que han de ser desarrolladas en otras Declaraciones y Avisos que, con la misma fuerza que aquellas, las "acomoden" a los "tiempos, lugares y personas"13. Dentro de esta vocación expansiva, la Compañía de Jesús fue el brazo militar de una ascética, que se edificó sobre la movilización allá donde las brasas del demonio aparecieran, con el salvífico remedio espiritual que las sofocara. Poco queda por saber de la unión de la ética protestante y el espíritu del capitalismo. Quizás quepa reparar, más bien, en la división realizada entre un "ethos"

\footnotetext{
10 Michel Foucault, "La scrittura di sè" (traducción italiana de Fabio Polidiri), Aut-Aut, no 195, 196, mayo-agosto de 1983, (traducción de Tomás Abraham "La escritura de si", Los senderos de Foucault (Tomás Abraham), Buenos Aires, Ediciones Nueva Visión, pp. 175-189.).

11 Atanasio, Vida de Antonio (introducción, traducción y notas de Paloma Rupérez Granados), Madrid, Editorial Ciudad Nueva, 1995.

12 Vid. Julián Lozano Navarro, La Compañía de Jesús y el poder en España de los Austrias, Madrid, Cátedra, 2005.

13 Ignacio de Loyola, "Proemio. Constituciones de la Compañía de Jesús", Obras de San Ignacio de Loyola, op. cit., p. 495.
} 
empresarial, encarnado en el protestantismo, y un "ethos" burocrático y político, materializado por el catolicismo. Ambas disposiciones morales, se construyeron sobre sendos miedos, según Schmitt nos hizo saber. El protestantismo se formó en la inquietud por la aparición de cualquier burocracia y en la confianza en la "era mecánica". El catolicismo se perfiló en la inquietud ante el aparato técnico económico moderno y en el esfuerzo por construir una maquinaria burocrática y jerárquica célibe. El "ethos" católico consideraba a la economía como algo extraño y sólo aquel que no practicaba rigurosamente la ascesis jesuítica podía dedicarse a los negocios. Quien respondía a la ascética católica practicaba la limosna y la mendicidad como parte de una gracia religiosa. Solo el calvinismo invirtió la apreciación positiva que había predominado de la caritas. Para el calvinismo, sólo Dios es responsable del reparto desigual de los bienes y el pobre más que un amigo es el responsable indolente de su precariedad ${ }^{14}$. Dentro de este argumento, el catolicismo destaca por su sedentarismo, por su apego a la tierra de donde recluta a sus sacerdotes. Un "terrismo" necesario para la petrificación paulatina de la "máquina burocrática". Muy al contrario, en el protestantismo habría predominado una movilidad espacial que es propia de la industria y del dinero. La Compañía de Jesús responde a ese modelo ascético burocrático, pero no sigue esa inmovilidad y rigidez que Catolicismo y fórmula política (1923-1925), de Schmitt, atribuye a la "organización eclesiástica" como si se tratara de un "carro blindado"15. En realidad, de las "pesadas masas monásticas" se pasó, con la Compañía de Jesús, a un "ejército de tropas ligeras"16. La Compañía de Jesús debió oponerse al protestantismo en una lucha dentro de su propia movilidad. Tampoco creo que la Compañía de Jesús se subsuma en la tipología del catolicismo, ofrecida por Schmitt, cuando le atribuye una fuerza representativa refulgente al catolicismo -el Papa, el Monje, el Vaticano, son sus grandes figuras- que no posee el parlamento, como representación supuesta de la soberanía del pueblo o de la Nación. La fuerza que le da el éxito al catolicismo es disciplinaria -aquí la Compañía de Jesús será ejemplar- y no representativa o carismática. En primer lugar, creo que la representación parlamentaria es mayor que la de la Iglesia y que el argumento schmittiano es capcioso, como mostraré al final. Creo, más bien que seguir disciplinadamente al Papa no requiere atribuirle dotes singulares, extraídas de entre las ruinas de lo imaginario dejadas por la hiperracionalización formal del

${ }^{14}$ Max Weber, Wirtschaft und Gesellschaft Grundriss der Verstehenden Soziologie (edición preparada Johannes Winckelmann), Tubinga, J. C. B. Mohr (Paul Siebeck), 1922 (nota preliminar José Medina Echevarría; traducción de José Medina Echevarría, Juan Roura Parella, Eugenio Ímaz, Eduardo García Maynez y José Ferrater Mora, Economía y sociedad, México, Fondo de Cultura Económica, 1944 (4ª reimpresión 1979), pp. 440, 461).

15 Carl Schmitt, Römischer Katholizismus und politische Form (estudio preliminar, traducción y notas de Carlos Ruiz Miguel Catolicismo y fórmula política, Madrid, Tecnos, 2000).

16 Émile Durkheim, L'évolution pédagogique en France, París, Presses Universitaires de France, 1938 (2 $2^{a}$ ed. 1969) (traducción de María Luisa Delgado y Félix Ortega Historia de la Educación y de las Doctrinas pedagógicas. La evolución pedagógica en Francia, Madrid, Las Ediciones de La Piqueta, 1982). 
mundo moderno. Ser elegido Papa requiere más bien haber sobresalido en la mortificación de lo singular, de la carne. Para el Catolicismo, sólo Dios realiza los milagros que se requiere para que no se agoste el carisma por la inevitable rutina social. El sacerdocio católico siempre es un oficio realizado a imitación de Cristo y no requiere creación carismática alguna ${ }^{17}$. Este tono monótono de la política y la burocracia católicas otorga un "ethos" peculiar y distinto al catolicismo como "formula política".

La vida de San Ignacio de Loyola (1587) y el Tratado de la Religión y Virtudes que debe tener el príncipe cristiano para gobernar y conservar sus Estados contra lo que Nicolás Maquiavelo y los políticos de este tiempo enseñan (1595), de Pedro de Ribadeneira ${ }^{18}$, contribuyen decisivamente al establecimiento de las dos tipologías sociales del funcionario y el político en el mundo católico. Mientras el primer tratado está dedicado al encomio de la obediencia, el segundo, también conocido como El Príncipe Cristiano, subraya la prudencia y la fortaleza como clave de bóveda de las virtudes cristianas del príncipe. El primer tratado es menos un panegírico del santo que una defensa de los tres votos de la Compañía de Jesús: pobreza, castidad y obediencia. No buscar cargos ni fuera ni dentro de la Compañía ha sido un propósito confeso de su fundador. Esta intencionada disminución de cualquier personalismo, o la concepción del carisma religioso como puramente instrumental, en beneficio del dominio de la grey, no favorece el elogio del santo. Ribadeneira parece recapacitar sobre la vida de Ignacio bajo la consideración de su dicho: no hacer nunca elogio de nadie hasta que no esté muerto. A veces, la biografía de Ignacio se diluye en el énfasis en las virtudes de otros fundadores y del pormenor de los progresos y logros de la Compañía. Dentro de un género memorialístico, Ribadeneira traza un retrato exaltado de Ignacio de Loyola durante el periodo de conversión de este militar guipuzcoano que acaba abominando de sus anteriores pecados y fundando la Compañía de Jesús. Todo el viaje iniciático de Ignacio, lleno de durezas, a Jerusalén para convertirse en soldado de Cristo contra la Reforma protestante es alabado. Su peregrinaje es narrado con un deliberado propósito ejemplar: el rechazo de su linaje noble, el acopio de un ideal de pobreza, la mendicidad, la renuncia y privación, la penitencia para llamar a Dios, la sepultura de los pecados anteriores, la bonhomía con los pobres,

${ }^{17} \mathrm{La}$ tesis de Weber sobre el carisma en un sentido puro subraya, en cambio, su encarnación en la Compañía de Jesús. El carisma en este sentido, según el sociólogo, es vocación o misión ascéticas, apartadas de la economía. El rechazo de la acumulación económica diaria y el menosprecio de los cargos en la Compañía de Jesús son ejemplos de un carisma puro (no político). Pero Schmitt va mucho más lejos al atribuir representación a la Iglesia, dando un sentido político a las "figuras" eclesiásticas. Vid. Max Weber, Economía y sociedad, op. cit., pp. 196, 850, 851.

18 Pedro Ribadeneira, Vida de San Ignacio, Barcelona, Imp. y Librería de la Viuda é Hijos de J. Subirana, 1885; Pedro de Ribadeneira, Tratado de la Religión y Virtudes que debe tener el príncipe cristiano para gobernar y conservar sus estados contra lo que Nicolás Maquiavelo y los políticos de este tiempo enseñan, Biblioteca de autores españoles. Obras escogidas del Padre de Ribadeneira de la Compañía de Jesús con una noticia de su vida y juicio crítico de sus escritos por Don Vicente de la Fuente, Madrid, Atlas, 1952, pp. 449-587. 
el desasosiego producido por la conversación con los hombres, el proselitismo y la captación de nuevos soldados, el ánimo de formar una Compañía con una "disciplina regular" son algunos de los rasgos de un personaje ejemplar que responde a la revelación de Cristo y de la Virgen. Pero una vez elevado Ignacio a la más alta responsabilidad de la Compañía en Roma, y ya impedido por sus compañeros para rehusar el mando por ser su aceptación más conveniente a la propagación del mensaje divino frente al hereje, comienza una sorprendente alabanza de los miembros del engranaje de una burocracia militar cada vez más compleja, más que del Fundador.

La subordinación de toda la Compañía a un solo capitán requiere ablandar los rasgos personales de cada soldado, incluso de su fundador. El más destacado personaje de esta Vida... es Cristo y la Compañía de Jesús, y no los milagros de un infatuable santo. Labrar la anatomía del novicio, dentro de esta concepción jesuítica, es un requisito para aprovechar sus dotes instrumentales y poner a cada uno en el oficio que más le conviene: ya sean los hombres hechos y consumados en letras; los instruidos y maduros que pueden ayudar en los oficios espirituales; los mozos hábiles, dotados de ingenios y esperanzas; o los legos que se ocupan de los oficios domésticos. La salvación no ya individual sino social requiere más de la disciplina uniforme que de la dirección carismática. La aportación de un "sistema disciplinario" por los jesuitas ha sido la causa de su éxito y la labor en que demostraron más "arte y originalidad"19. Sólo la realización acrítica de una orden y la uniformidad de la acción ordenada, logradas mediante el poder de una "disciplina racional", pueden lograr la extensión de su dominio. De aquí la voluntad de la Compañía de Jesús de organizarse como una "comunidad de ascetas", sometidos a una disciplina sobre sí mismos que pudiera permitirles empresas espectaculares sobre el mundo ${ }^{20}$. El riesgo de una empresa que debía afrontar el martirio ejecutado por el hereje protestante, el canibalismo brasileño, o los límites reales y simbólicos, hasta entonces infranqueados, de culturas amuralladas como la japonesa, requirió de una obediencia sin límites a la autoridad, en última instancia institucional del Papa, a la vez que necesitó del reconocimiento histórico de estas hazañas religiosas. Más importante incluso que mandar, dentro de la lógica de la Vida de San Ignacio, es obedecer. De tal forma que los obedientes miembros de la Compañía, cuando emprendían una empresa en lugares lejanos e inhóspitos, acudían en parejas y se iban alternando en los papeles de mando y obediencia para impedir que se olvidara el importantísimo "voto de obediencia". Además, a su fundador le parecía estar más preparado para obedecer que para mandar y apreciaba más la obediencia para cumplir la salvífica "mortificación de la carne".

Dentro de la tipología social de la Compañía, la obediencia es la mayor virtud del religioso. La obediencia es tenida por Ribadeneira, dentro del ideario marcado

19 Émile, Durkheim, Historia de la Educación y de las Doctrinas pedagógicas. La evolución pedagógica en Francia, op. cit., pp. 325-331.

${ }^{20}$ Max Weber, Economía y sociedad, op. cit., pp. 882, 883, 900-903. 
junto a Ignacio de Loyola, como la marca de diferencia de esta orden sobre otras religiones. Ha de ser una obediencia ciega que comprometa, sin fisura alguna, al juicio y a la voluntad. Su cumplimiento riguroso requiere tanto su satisfacción exterior como interior, sin consideración o cálculo prudencial. Se considera que la prudencia es virtud de quien manda pero no de quien obedece. Se trata de contrarrestar lo querido con lo contrario para, así neutro, obedecer. Así detalla Ribadeneira la obediencia de Ignacio de Loyola a su superior, el Papa: «Siendo ya General de la Compañía dijo diversas veces, que si el Papa le mandase que en el puerto de Ostia (que es cerca de Roma) entrara en la primera barca que hallase, y que sin mástil, sin gobernalle, sin vela, sin remos, sin las otras cosas necesarias para la navegación y para su mantenimiento, atravesase la mar, que lo haría y obedecería no sólo con paz, mas aún con consentimiento y alegría de su ánima. Y como oyendo esto un hombre principal se admirase, y le dijese: "¿Y que prudencia seria esa?" respondió el santo Padre: "La prudencia, señor, no se ha de pedir tanto al que obedece y ejecuta, cuanto al que manda y ordena." ${ }^{21}$ Ribadeneira había trascrito así, muy weberianamente, con gran anticipación el tejido complejo de las relaciones entre el funcionario y el político modernos. Pero todavía habrá que esperar a la aparición del Estado burocrático y a la democracia de masas para estar ante dos tipos tan diáfanamente diferenciados. Por el momento, la obediencia es un camino privilegiado para lograr la muerte, la anulación de la voluntad y el dominio auténtico del Señor.

\section{Un política monista y providencialista}

Sin embargo, la construcción de la empresa jesuítica requirió no sólo de las piezas acopladas de una máquina burocrática eclesiástica. La empresa jesuítica dispuso una concepción antimaquiaveliana maquiavélica de la política muy apoyada en la difusión de El príncipe (1513-1516) y de las doctrinas "gentiles", convenientemente manipuladas 22 . El disimulo, la utilidad de los medios malévolos y la diplomacia son característicos del maquiavelismo y no están exentos en el jesuitismo. Ya Ribadeneira cree interpretar el sentir de Ignacio de Loyola cuando aconseja utilizar tan "buenas palabras" cuando se expresa una voluntad negativa, que el otro "si es posible vaya tan amigo y tan gracioso como vino"23; o utilizar la "simplicidad de la paloma" y la "prudencia de la serpiente"24. La utilización de fondo del maquiavelismo político pervivió con un gradual rechazo formal de la figura de

21 Pedro Ribadeneira, Vida de San Ignacio, op. cit., p. 516.

22 Para estudiar la conformación del antimaquiavelismo político, Vid. el excelente estudio de José María Iñurritegui Rodríguez, La Gracia y la República. El lenguaje político de la teología católica y el Príncipe Cristiano de Pedro de Ribadeneyra (prólogo de Pablo Fernández Albadalejo), Madrid, Universidad Nacional de Educación a Distancia, 1998.

23 Ibid. pp. 604, 605.

24 Ibid. p. 602. 
Maquiavelo. Se ha distinguido entre una primera y una segunda contrarreforma -la del quinientos, de signo religioso; y la del seiscientos, de identificación política-, en las que gradualmente se articula este rechazo formal no sólo de Maquiavelo sino, también, de Tácito y de Bodino25. Hasta que los herejes no empiezan, según la Iglesia, a utilizar al autor de La Mandrágora (1518), la desautorización de Maquiavelo no es política sino doctrinal. El desacuerdo se limita al plano de los argumentos y de la conveniencia de sus postulados. Carlos V aconseja que sea leído por los príncipes y se precia de hacer así en el privilegio a su traducción por Juan Lorenço Otevanti de 1552. Con la prohibición de Roma, Maquiavelo aparece en el primer Índice autónomo de autores prohibidos de Quiroga en 1583.

La primera oposición ético-religiosa a Maquiavelo la sostiene Pedro de Ribadeneira por haber otorgado el florentino a la política un mero valor histórico y mundano. Los fines trascendentes de la religión cristiana, para Maquiavelo, no habrían contribuido sino al declive del imperio romano. Lo que a Ribadeneira no podía sino parecerle una imputación impía. Los mayores esfuerzos de actitud antimaquiaveliana los protagonizó la Compañía de Jesús en su desprecio a la justificación protestante del tirano. La Compañía consideraba que la más patente definición del tirano se encontraba en El Príncipe ${ }^{26}$. Pero el aprovechamiento teórico del florentino que destilan los argumentos de El Príncipe Cristiano de Ribadeneira hace pensar en su imposible construcción teórica sin su exhaustivo conocimiento. Lo que diferencia claramente la concepción jesuítica de la maquiaveliana es, de una parte, el monismo valorativo y el politeísmo valorativo, de otra; así como, de una, la "mortificación de la carne" y el júbilo pagano que les caracteriza, de otra. No deja de ser abundar en el polimorfismo interpretativo de Maquiavelo -ya suficientemente complicado por las interpretaciones republicanas y monarquistas- el atribuirle ser un precedente del liberalismo, pero, al menos bajo estos dos polos diferenciadores del catolicismo y del humanismo, no deja de haber una línea de continuidad entre el naturalismo del autor de los Discursos sobre la primera década de Tito Livio (1515-1518) y el de un representante tan genuino del liberalismo del siglo XIX, como John Stuart Mill. Se conoce la admiración de éste por aquel ${ }^{27}$. Una admiración que sólo podría aparecer como blasfema, como veremos al final. Entre una y otra concepción se juegan dos versiones de la política: la de una virtud responsable y activa, que debe bascular entre los acontecimientos contingentes de la Fortuna (Capítulos XVIII y XXV de El Príncipe)28; y la de una virtud vicaria de Dios, que acata, en última instancia,

25 Para analizar el papel jugado por Ignacio de Loyola entre el Renacimiento y la Contrarreforma, Vid. Ricardo García-Villoslada, Loyola y Erasmo. Dos almas, dos épocas, Madrid, Taurus, 1965.

${ }^{26}$ Enrique Tierno Galván, El tacitismo en las doctrinas políticas del siglo de oro español, Murcia, Sucesores de Nogués, 1949, pp. 22-27.

27 John Stuart Mill, Diario (Carlos Mellizo Ed.), Alianza Editorial, 1996, pp. 25-27.

${ }^{28}$ Nicolás Maquiavelo, Il Principe (traducción e introducción de Miguel Angel Granada, El Príncipe, Madrid, Alianza Editorial, 1981 (12ª reimpresión 1993), pp. 90-93, 116-120). 
los sucesos necesarios dispuestos por la ineluctable Providencia ${ }^{29}$. De la primera es ejemplo de comportamiento un hombre sin escrúpulos, César Borgia o el Duque Valentino, dispuesto a descuartizar públicamente a su mejor aliado en propio beneficio con el mejor postor; de la segunda es modelo el calvario de Cristo. Entre la contingencia y la necesidad de una y otra se expresan, también, como veremos, dos modelos de política para la modernidad: la de la "razón de Estado" maquiaveliana y la del "poder pastoral" cristiano.

Las dos partes de El Príncipe Cristiano de Ribadeneira se refieren, respectivamente, a los deberes del príncipe con la Iglesia y la religión, y a los consejos seculares y profanos sobre la organización política, sus sostenedores y sus responsables. La execración de Ribadeneira contra los políticos se basa en la utilización de una razón de Estado que, en vez de situar a la ley de Dios como fin y justificación últimos, postula concebir a la religión como un medio. Maquiavelo habría infectado rápidamente toda Europa, a su muerte, con una concepción instrumental de la religión. Como el florentino habría incurrido en una falsificación de la razón de Estado, Ribadeneira quiere distinguir entre dos razones de Estado, una de ellas sería la corregida de acuerdo con la doctrina católica. Este propósito analítico pasa por la presuposición de un mundo absolutamente caracterizado por la primacía total de la religión católica y la atribución a Dios de ser causa primera del mundo. En definitiva, los escuadrones de caballeros excelentes, agrupados en una milicia sagrada, que configuran la Compañía de Jesús, poseen un rango mayor que los reyes de la tierra, dentro de la escala política, dado que Dios es el capitán general de estos padres religiosos y el gran Padre temible que ayuda o arrastra a la caída al Príncipe cristiano, según siga o no su palabra divina. Uno de los mandamientos más terminantes de El Príncipe Cristiano es el respeto de los príncipes terrenales a los sacerdotes y ministros espirituales de Dios. Dios es el más grande Rey, causa eficiente, Providencia de los cielos y de la tierra, señor sobre el libre albedrío de los hombres y temor profundísimo y reverencial de todo rey terrenal.

La gran equivocación de los políticos es, entonces, instrumentalizar la religión, mostrar una creencia meramente externa, sin reparar en la fuerza dispensadora de la Providencia. De ahí que no quepa suponer -a diferencia de lo que mantienen los políticos maquiavelianos- poder y prudencia del Estado si falta la religión como primer fin. Si Maquiavelo consideraba que más valían las buenas armas que las buenas leyes, pues para que haya buenas leyes deben haber buenas armas, Ribadeneira opina que si no hay respeto absoluto a la religión católica, no puede haber buenas armas. Dios sólo da el triunfo a quien le sigue. La religión, para el tratadista español, es el principal cuidado del príncipe frente a la falsa razón de Estado. La potestad divina está por encima de la potestad regia o humana y han

29 Julián Sauquillo, "Providencia y Poder pastoral en el Príncipe Cristiano de Quevedo", Horizontes de la Filosofía del Derecho. Homenaje al Profesor Luis García San Miguel (II) (Virgilio Zapatero, Ed.), Alcalá de Henares, Universidad de Alcalá, 2002, pp. 707-736. 
de saber, por ello, los reyes que sólo poseen la prudencia, en el mejor de los casos, para organizar sus reinos, elegir los magistrados adecuados o demandar los tributos oportunos. Pero que carecen de la prudencia de los "pastores eclesiásticos", únicos capaces de entender las sagradas escrituras y "penetrar en los divinos misterios" que deben conducir al rebaño de creyentes. Al Rey se le pide mayor rigor en el acatamiento de Dios que a los mortales y si comete un delito ha de humillarse bajo Dios en igual penitencia que los otros hombres.

A partir de esta consideración de una sola interpretación verdadera, se organiza un dispositivo doctrinal y político de execración de todos aquellos considerados como enemigos de la fe auténtica. Nada peor que la duda dentro de la fe aceptada. Si existe una dicotomía absoluta entre fieles y paganos, o entre fieles y gentiles, peor aún resulta la herejía dentro de la fe. El bautizado ha realizado una elección inamovible. Toda quiebra o fractura del compromiso católico es una alta traición que debe ser castigada por el príncipe sin perdón. Toda la opinión cristiana ha de acatar, sin duda alguna, la existencia de una única fé verdadera. En sus límites, sólo queda la intolerancia, la persecución, el castigo o la expulsión. La excomunión o el anatema, la excomunión con solemnidad, supone, muy gráficamente, nada menos que la salida de la Iglesia de los herejes "apartados y cortados, como miembros secos, del cuerpo de la santa Iglesia" 30 . Para Ribadeneira no hay duda de que perseguir cualquier división sectaria o herética, infectiva de la república, es un principal cometido cristiano del príncipe sobre la tierra.

\section{El "poder pastoral" como "arte de gobernar"}

La parte profana del tratado reúne, más explícitamente, el debate doctrinal con las tesis de Maquiavelo. Si "Il Machia" había propugnado el disimulo de las auténticas intenciones y el empleo de cualquier fin en aras del mantenimiento y extensión de la república, Ribadeneira, sobre el plano de los principios generales, sostiene que las verdaderas virtudes son cristianas y no pueden ser fingidas pues serían redoblada maldad. No se trata, como para Maquiavelo, de ser temido sin ser odiado, en vez de ser amado por el pueblo, sino de ser querido por Dios, ya que es la opinión que el creador tenga del rey terrenal, y no la opinión de los hombres, la que quita los Estados. Aunque Ribadeneira y Maquiavelo podrían haber coincidido en desechar la política de oposición al Papa protagonizada por Savonarola, las motivaciones de uno y otro serían muy diversas. El primero habría rechazado la oposición a una jerarquía eclesiástica incuestionable para el jesuitismo político; mientras que el segundo tachó de ingenua cualquier oposición frontal a la política tradicional y pusilánime del Papa. Para Ribadeneira más abusivo de lo ordenado por Dios sería aún la utilización de la religión como máscara, tal

\footnotetext{
30 Pedro Ribadeneira, Tratado de la religión y virtudes, op. cit., p. 508.
} 
como aconseja hacer Maquiavelo a un príncipe que ha de ser un taimado hipócrita, que la oposición frontal a Dios. En realidad, en el plano de los hechos, Ribadeneira rebajará, en El Príncipe Cristiano, la prohibición del disimulo pues acaba justificando maquiavélicamente la disimulación con el disimulado siempre que no se rebase el límite en el que Dios pueda ofenderse: “(...) así desta simulación y ficción artificiosa se debe usar solamente cuando lo pide la necesidad, y que sea poca la cantidad y con su dosis y tasa, y conficionada con las leyes de la cristiandad y prudencia, porque así aprovechará y tendrá fuerza y virtud contra los príncipes hipócritas, que, como víboras, pretendiesen inficionar y matar. (...)"31. Además, mediante una distinción puramente retórica, Ribadeneira establece que guardar secreto y recatarse no es mentir ${ }^{32}$.

Tanto Maquiavelo como Ribadeneira construyen su teoría del poder frente al arbitrio y discrecionalidad del tirano. Ni uno ni otro conciben justificar las actuaciones políticas por el beneficio o el capricho del príncipe. Para Maquiavelo, el príncipe malo siempre obra mal pues es casi imposible que pase de actuar en beneficio propio a querer para el beneficio de la república. Difícil será encontrar un hombre bueno que pase a ser malo, en los momentos de excepcionalidad política, cara a remontar, con medidas dictatoriales, la corrupción de la república en un tiempo limitado. Pero la generosidad del tirano es inconcebible para Maquiavelo incluso si su magnanimidad beneficiase a la república (Capítulo XVII y XVIII del Libro I de los Discursos sobre la primera década de Tito Livio) ${ }^{33}$. Sin embargo, el príncipe republicano de Maquiavelo puede llegar a salvar a la republica y sacrificar a los republicanos, por puro refinamiento de la lógica implacable de unos medios que están justificados por un fin impersonal. A fin de cuentas, una finalidad básica de la política maquiaveliana es mantenerse en el poder conquistado. Maquiavelo siempre observa el poder como separado del pueblo, elevado del nivel del mundo, y amenazado. Mientras que Ribadeneira procura justificar un poder que emana del beneficio logrado en el seno del pueblo. La diatriba de Ribadeneira con las tesis de Maquiavelo se cierra con la valoración de la prudencia y la fortaleza de que debe hacer acopio del príncipe. Si la política maquiaveliana recomienda el arrojo y la temeridad, en última instancia, porque saber acoplar y limitar la propia psicología, más amedrentada o más emprendedora, a cada ocasión diversa, y lograr así el triunfo, es lo más difícil que quepa concebir, Ribadeneira parece haber perfeccionado, incluso, el arte de la administración de la fuerza dentro de una concepción del "poder pastoral".

En la recomendación del consejo político y en las reglas de la prudencia, Ribadeneira es un fiel seguidor de Maquiavelo. En cuanto a que se le haya podido

\footnotetext{
31 Ibid. p. 526.

32 Ibid. pp. 524, 525.

33 Nicolás Maquiavelo, Discorsi sopra la prima deca di Tito Livio (introducción, traducción y notas de Ana Martínez Arancón, Discursos sobre la primera década de Tito Livio, Madrid, Alianza Editorial, 1987, pp. 81-87).
} 
discutir la fortaleza al cristianismo, Ribadeneira es el teórico irritado que no consiente que se le merme tal crédito a los mártires y a los arrojados soldados religiosos de la Compañía de Jesús. Así que no se trata tanto del acopio de la fuerza o de la demostración de fortaleza sino de la administración de estas dotes y herramientas políticas en la captación de una grey seguidora, primero, y en su defensa, consiguiente, de sus enemigos. El demonio, la cizaña, los lobos no deben reducir el trabajo del pastor: la salud del rebaño de la república cristiana. Para la consecución de este fin, Ribadaneira predica unas reglas de administración de los recursos adecuadas al bienestar y al aprovechamiento del rebaño. Sin uno no hay otro. Por ello, el "reloj de la república" debe aplicar los castigos y no descuidar el empleo de los premios ${ }^{34}$. Ribadeneira postula la bondad de los premios, la magnanimidad, la atención a los merecimientos venidos del esfuerzo de la grey y no agotar la rentabilidad del rebaño asfixiándole con los tributos. El pensamiento de Ribadeneira es precomercial, pues muestra una confianza hacia la agricultura comparable en grado al recelo que le produce el comercio como fuente de necesidades vanas que pueden contribuir a la corrupción de la república ${ }^{35}$.

La expansión de la misión jesuítica fue descrita por Ribadeneira con el orgullo de quien contribuye a la formación de una empresa internacional inédita. Razones para esta ilusión emprendedora no le faltaban. El barroco español ha contribuido decisivamente a la configuración de un "poder pastoral" capital en la formación del poder moderno. La reflexión de Ribadeneira se encuentra enclavada más en una racionalidad que afecta al proporcionamiento por el gobierno de la seguridad a una población dentro de un territorio que en el interés del príncipe republicano. El Príncipe Cristiano y La vida de San Ignacio de Ribadeneira, y Las Constituciones de Ignacio de Loyola son menos "consejos de príncipe", al uso, que unos tratados que irrumpen en la historia política europea, según Michel Foucault, desde la mitad del siglo XVI hasta finales del siglo XVIII, para mostrar un nuevo "arte de gobernar": cómo ser gobernados, cómo gobernar a los otros, a quién aceptar como gobernante, cómo hacer para ser el mejor gobernante posible. Mientras el "consejo de príncipes" señala una posición singular, excepcional, externa a los gobernados y siempre amenazada por las traiciones -el Hieron de Jenofonte es ejemplar en esta problemática antigua-, el "gobierno" es un poder inmanente a múltiples relaciones sociales: gobierno de una casa, del alma, de los niños, de una provincia, de un convento, de una orden religiosa, de una familia,..... ${ }^{36}$. La Compañía de Jesús ha tenido una importancia excepcional en

34 Pedro Ribadeneira, Tratado de la religión y virtudes, op. cit., pp. 530, 531.

35 Ibid. pp. 530-539.

36 Michel Foucault, "La «gouvernamentalitá»", Aut-Aut, no 167-168, 1978, pp. 12-29 (traducción francesa de Jean-Claud Oswald, revisión y anotación Pascale Pasquino "La "gouvernamentalité", Actes, n 54, verano de 1986, 91 pp. 6-15; traducción de Julia Varela y Fernando Álvarez-Uría "La gubernamentalidad”, Espacios de poder (Michel Foucault et alii), Madrid, Las Ediciones de La Piqueta, 1981, pp. 9-26); Michel Foucault, «Leçon de $1^{\mathrm{er}}$ février 1978», Sécurité, territoire, population. Cours au Collège de France, $1977-$ 1978, París, Gallimard Seuil, 2004, pp. 91-118. 
la conformación de este "poder pastoral" polimorfo que rebasa los límites del gobierno político del príncipe. La directrices de la Compañía de Jesús trazan una línea de continuidad entre el gobierno espiritual de los ejercicios; el gobierno económico, a través de la caridad y los patrocinadores que acuden como muestra del apoyo de Dios; y el gobierno político, al construir un tipo de príncipe plegado al poder eclesiástico. Ética, economía y política están interpenetrados en la teoría del poder de los jesuitas. No se trata de construir un poder político sino de asegurar un orden social en el que Dios está presente en todo, incluso en las más pequeñas cosas. Sus invocaciones a la religión como ley divina a la que se pliegan todas las cosas no descuidan que sólo una buena costumbre puede contribuir a la salud de la república cristiana. La estipulación de un poder disciplinario, basado en la obediencia al superior y el desempeño individual perfecto de una función orgánica, determina un imperativo moral de acatamiento. El cuidado del rebaño, su explotación sin desfallecerlo, los estímulos a la contribución del bienestar del colectivo, la concepción de los bienes como bien común y no del príncipe, la empresa del príncipe de guardián de los bienes de todos en vez de dilapidador de los bienes públicos son las pálidas huellas de una economía colectiva. La formulación de un poder del principado como vicario de Dios asegura el repliegue del poder civil al poder eclesiástico. Ética, economía y política contribuyen, a su manera, en el sostenimiento de un mundo controlado y libre de contingencias. La necesidad no se da, se construye con la sabia disposición de todas las cosas públicas y privadas. Para asegurar la obediencia a las leyes, la Compañía de Jesús ha establecido un correcto aprovechamiento de unos recursos humanos espléndidos y económicos modestos, a los fines de expandir una empresa religiosa internacional para la salvación del mundo del maleficio hereje que supone el protestantismo. Aunque declarativamente, a través del tomismo, la Compañía de Jesús asume toda la concepción teleológica neoaristotélica, bien se ocupa de asegurar su cumplimiento con una cuidada disposición táctica de todas las cosas, por pequeñas que sean. Una racionalidad militar permea toda la movilización jesuítica más allá de la declaración de leyes naturales o divinas.

\section{El liberalismo es irreductible a la "complexio oppositorum"}

La preparación del eclesiástico como un soldado obediente a su capitán requirió de una ascética de valor incalculable para la nueva sociedad y la política venidera. La teoría sociológica clásica así lo ha apreciado bajo dos aspectos: la creación de una aristocracia espiritual o de una élite cultivada; y la difusión pedagógica de un modelo católico de vida. Desde la primera perspectiva, la salvación monacal jesuítica fue configurando un "ethos" racional y metódico de dominación de lo instintivo y de subordinación de toda la vida a lo religioso. Cuanto más se racionalizó este método, los capaces de su ejecución se convirtieron en una "aristocracia de calificados religiosamente" por la detentación de un 
prestigio social ${ }^{37}$. Desde el segundo, la única actividad que han admitido como justificativa, desde sus orígenes, de un bienestar económico en la Compañía es el estudio de los novicios. La atención pedagógica requiere -así lo predican Ignacio de Loyola y Ribadeneira, como máximos teóricos de la fundación de la Compañía de Jesús- una holgura que sólo permite el estar desentendido de las necesidades básicas. Esta genuina consideración de la satisfacción al estudio hace que la empresa jesuítica sea una empresa pedagógica ligada al proselitismo y a la supervivencia. Desde mediados del siglo XVI, la corporación jesuítica adquiere hegemonía en el control de la educación sobre la tenida, hasta entonces, por la Universidad en las enseñanzas renacentistas. La expansión del protestantismo, entonces, por Alemania, Suiza, Países Bajos, Suecia, y buena parte de Francia, fuerza a la Compañía de Jesús a salir de los claustros y ofrecerse como una milicia pedagógica. La causa de este éxito es que la Compañía de Jesús atendió a dos rasgos: propiciar un "clérigo regular" obediente y disciplinado, capaz de movilizarse donde la Iglesia lo necesitara; y procurar no enclaustrarse sino mezclarse con la sociedad. Para permear la sociedad de jesuitismo no bastaba con predicar, confesar y catequizar sino que era óptimo educar a la juventud. El retroceso que propiciaron con esta estrategia tan astuta fue de cuatro siglos. Paralizaron la humanización de la enseñanza y la retrotrayeron al santuario. La eficacia del obediente jesuita en su penetración dogmática en la sociedad fue tanta que uno de los mayores defensores de la educación laica y estatal en Francia no dudaba en conceder al jesuitismo haber contribuido, decisivamente, en la construcción de aquel "talante nacional" 38 . Esta última afirmación no es despreciable en ningún caso. La contribución de los jesuitas a la conformación del talante nacional de Francia, del país más tendente en la modernidad a la centralización administrativa y a la organización del modelo más evidente de Administración permanente, se dio con el modelo legal racional predominante en la modernidad y con la aparición del funcionario como sujeto que resuelve sine ira et studio.

Si el "ethos" económico se identificó, según Schmitt, al principio, con el protestantismo y el "ethos" burocrático y político con el católico, queda por considerar la correspondencia de esta tipología ideal con la realidad. Efectivamente, parece que la tesis weberiana de la relación inmediata de la "ética protestante" y el "espíritu del capitalismo", con sus revisiones clásicas y contemporáneas, se sustenta. Pero, ¿acaso Inglaterra con toda su industrialización pionera no dio lugar a ninguna realidad política? ¿Sólo hubo lugar en la revolución industrial para el desarrollo del "pensamiento económico-técnico dominante"? No lo creo. Hay buenas razones para considerar plausible la contribución importante del catolicismo a la "burocracia" y a su personaje central, el funcionario. Pero, ¿cuál es la contribución real del catolicismo a la construcción de la política moderna?, ¿es

${ }^{37}$ Max Weber, Economía y sociedad, op. cit., p. 427.

38 Émile Durkheim, Historia de la Educación y de las Doctrinas pedagógicas. La evolución pedagógica en Francia, op. cit., pp. 289-299. 
tanta como le atribuye Schmitt? No lo creo. Schmitt atribuye una fuerza inédita al jesuitismo, y al catolicismo en general, como complexio oppositorum capaz de captar como un imán a las fuerzas políticas más diversas y extremas -del filósofo de la dictadura autoritaria Donoso Cortés al rebelde sindicalista y nacionalista irlandés Padraic Pearsem- por la capacidad representativa de sus Figuras, sintetizadoras de la "Forma estética de lo artístico", la "Forma jurídica del Derecho" y el "Forma de poder histórico-universal de brillo deslumbrante". Schmitt, muy capciosa y sofísticamente, despoja de cualquier capacidad representativa a la burguesía al haber abolido las diferencias y sólo tener como término de contraste diferente a la bohemia. Si la burguesía es, desde la Revolución Francesa, la Nación, ni el comerciante ni el burgués representan a nadie. De una parte, donde hay fábrica y parlamento no cabe la representación. Si hay Producción y Consumo no hay Representación, pues, para que ésta se dé, es necesario una persona y una autoridad como representante y no hay Forma alguna en la fábrica y en el comercio. Sólo en el desapego económico del vicario de Cristo en la Tierra cabe la fuerza inédita representativa del Catolicismo. De otra parte, el parlamento, para Schmitt, reúne a la Nación, y así abole cualquier representación. El parlamento es, para Schmitt, otra complexio oppositorum pero sin ningún brillo, en esta caso: reduce la multiplicidad de intereses de los partidos a una unidad apagada.

Lo más escandaloso del argumento de Schmitt es que ha elegido al liberalismo más monista, al liberalismo revolucionario francés, para irradiar más iluminación al papel político de la jesuítica Iglesia. Pero, ¿acaso no hay una tradición más magnética y vitalizante de la política dentro de la tradición liberal? El mayor antagonista de Ribadeneira, Maquiavelo, representa un politeísmo valorativo irreductible a una complexio oppositorum apagada y abolidora de los contrastes. Maquiavelo, un noble valedor de los comerciantes en el beneficio de la república, es el gran defensor de las disyuntivas: "aut... aut...", "o... o...". En caso de conflicto, nunca permanezcas en el centro -aconseja-, alíate $o$ con unos $o$ con otros. Además, el conflicto para este pagano es consustancial a la vida. A este florentino que defendía la austeridad y la dificultad, como mejor camino para conseguir la "virtu", no le causaba duda alguna el valor del comercio a favor del relieve político de la república. Nada más perjudicial para la política de unificación italiana que un Papa que no luchó por la conquista y sostenimiento del papado. Los regalos hereditarios no indican el camino de la virtud. Para Maquiavelo, la atrocidad del combate, de la lucha, y no "Roma aeterna", es la Forma patriótica fascinante.

Pero ¿pudo la revolución industrial acabar con la tradición maquiaveliana que impregnó a los "igualitaristas" ingleses? No lo creo. A mediados del siglo XIX, la economía refulgente no ha humillado a la política. La monótona y homogeneizante complexio oppositorum del catolicismo, de una parte, y el desarrollo económico inglés, de la otra, no impiden la opinión politeísta de John Stuart Mill: "los cambios efectuados progresivamente en la sociedad moderna tienden cada vez más a poner de manifiesto con mayor vigor: la importancia que, para 
el hombre y para la sociedad, posee el hecho de que exista una gran variedad de tipos de carácter, y la importancia de dar completa libertad para que la naturaleza humana se expansione en innumerables, opuestas direcciones." 39 Esta es la única verdad de On Liberty (1859). La propia burguesía no sólo no ha consumido la posibilidad de representación sino que supone que en un mundo contingente y sin verdad dada alguna, el contraste recíproco de las opiniones es la única vía de formación social de verdades provisionales y compartidas. Lo que más teme la burguesía ilustrada animada por John Stuart Mill es que el poder social, más temible que el poder político, acabe con la disidencia, la apostasía, la herejía. Los más extravagantes -no la bohemia supuestamente melancólica, decadente y apagada, a la que se refiere Schmitt- son la planta rara que atiza como un tábano -los nuevos sócrates- a la sociedad: "Cuando se encuentran personas que forman una excepción en la aparente unanimidad del mundo sobre cualquier asunto, aunque el mundo esté en lo cierto, -señala Mill- es siempre probable que los disidentes tengan algo que decir que merezca ser oído, y que la verdad pierda por su silencio." 40 Sólo cuando la sociedad no es madura, cabe justificar como oportuna la tutela religiosa que los jesuitas ejercieron en Uruguay. Cuando la sociedad cuenta con el vigor del debate, los hombres enérgicos deben dirigir la máquina burocrática pues todo aparato inanimado, y la Administración lo es, para ser eficaz, requiere una fuerza exterior que la anime ${ }^{41}$. Requiere del carisma liberal y, más originariamente, pagano.

El punto de partida de esta política liberal es moral. La representación de los personajes liberales surge del paganismo y no del cristianismo. Para esta política liberal clásica, menospreciada por el catolicismo de Schmitt, la moral cristiana tiene todos los caracteres propios de la reacción y el corsé de las almas. La protesta cristiana frente al paganismo, que tan ejemplarmente protagonizó el jesuitismo moral y político, postuló un "ideal negativo", pasivo, reactivo, abstinente, renunciante, mortificante. Una ascesis aterrorizada de la sensualidad impidió, mientras pudo, esta ascesis vigorizante del liberalismo, surgida junto al desarrollo técnico-económico. La negación cristiana de uno mismo no logró, sin embargo, agostar la afirmación pagana de la individualidad. La complexio oppositorum del jesuitismo encuentra así un término no asimilable en la tradición más intempestiva del liberalismo.

39 John Stuart Mill, Autobiography (prólogo, traducción y notas de Carlos Mellizo, Autobiografía, Madrid, Alianza Editorial, 1986, p. 239).

40 John Stuart Mill, On Liberty, Londres, Oxford University Press, 1969 (prólogo Isaiah Berlin, de Pablo de Azcárate, Sobre la libertad, Madrid, Alianza Editorial, 1970 (3ª ed. 1981), p. 114).

41 John Stuart Mill, Representative government (presentación Dalmacio Negro, traducción de Marta C. C. Iturbe Del gobierno representativo, Madrid, Tecnos, 1985). 